\title{
PERAMALAN JUMLAH KEDATANGAN WISATAWAN MANCANEGARA KE SUMATERA BARAT MELALUI BANDARA INTERNASIONAL MINANGKABAU DENGAN MODEL SARIMA
}

\author{
PRAWATI NINGSIH, MAIYASTRI, YUDIANTRI ASDI \\ Program Studi S1 Matematika, \\ Fakultas Matematika dan Ilmu Pengetahuan Alam, Universitas Andalas, \\ Kampus UNAND Limau Manis Padang, Indonesia. \\ email : prawatiningsih96@gmail.com
}

Diterima 22 Juni 2019 Direvisi 6 Juli 2019 Dipublikasikan 4 Agustus 2019

\begin{abstract}
Abstrak. Jumlah kedatangan wisatawan mancanegara ke Sumatera Barat melalui Bandara Internasional Minangkabau cenderung mengalami perubahan di setiap tahunnya. Untuk mengetahui jumlah kedatangan wisatawan mancanegara di masa yang akan datang, dapat dilakukan dengan menggunakan model SARIMA. Model SARIMA merupakan model ARIMA yang mengandung unsur musiman. Model ini diaplikasikan untuk meramalkan jumlah kedatangan wisatawan mancanegara pada periode Januari 2019 hingga Desember 2019. Hasil analisis data menunjukkan bahwa model $\operatorname{SARIMA}(1,0,1)(2,1,0)^{12}$ yang terbaik, dimana hasil pendugaan yang diperoleh tidak jauh berbeda dari data aktual.
\end{abstract}

Kata Kunci: Wisatawan Mancanegara, Model SARIMA, Peramalan

\section{Pendahuluan}

Sumatera Barat adalah salah satu Provinsi di Indonesia yang terletak di Pulau Sumatera dengan Padang sebagai ibukotanya. Provinsi Sumatera Barat merupakan salah satu provinsi yang banyak memiliki tempat-tempat wisata yang sangat indah dan sangat diminati oleh wisatawan mancanegara. Selain tempat-tempat wisata yang sangat indah, Sumatera Barat juga memiliki daya tarik wisata yang sangat potensial yang dapat memikat wisatawan untuk berkunjung ke Sumatera Barat diantaranya daya tarik wisata alam, sosial dan budaya.

Berdasarkan data yang diperoleh dari website resmi Badan Pusat Statistik jumlah kedatangan wisatawan mancanegara melalui Bandara Internasional Minangkabau mengalami perubahan disetiap tahunnya. Untuk mengetahui perubahan jumlah kedatangan wisatawan mancanegara di Provinsi Sumatera Barat, pemerintah perlu melakukan peramalan dimasa yang akan datang. Data kunjungan wisatawan mancanegara ke Sumatera Barat merupakan data deret waktu (time series) dan data tersebut mengandung pola musiman, sehingga dapat dilakukan peramalan data deret waktu. Peramalan data deret waktu dilakukan dengan menggunakan 
pendekatan kuantitatif dengan data masa lampau dikumpulkan dan dijadikan acuan untuk peramalan masa depan. Untuk melakukan peramalan data deret waktu pada jumlah kedatangan wisatawan mancanegara ke Sumatera Barat yang memiliki pola musiman dapat dilakukan dengan menggunakan model Seasonal Autoregressive Integrated Moving Average (SARIMA).

\section{Beberapa Konsep Dasar}

\subsection{Autoregressive Integrated Moving Average (ARIMA)}

Model $A R I M A$ terdiri dari tiga parameter: $(p, d, q)$, dimana $p$ merupakan parameter autoregressive, $q$ merupakan parameter moving average, $d$ menggambarkan jumlah proses differencing. Secara matematis, model ini ditulis sebagai berikut [1]:

$$
\begin{aligned}
\phi_{p}(B) \nabla^{d} X_{t} & =\theta_{q}(B) \varepsilon_{t}, \\
\phi_{p}(B)(1-B)^{d} X_{t} & =\theta_{q}(B) \varepsilon_{t},
\end{aligned}
$$

dimana $\phi_{i}$ adalah koefisien $A R$ dengan orde $p, \theta_{i}$ adalah koefisien $M A$ dengan orde $q$, dan $\nabla^{d}$ adalah differencing dengan orde $d$.

Untuk mendapatkan nilai $p$ dan $q$ pada model $A R I M A(p, d, q)$ dilakukan dengan melihat plot fungsi autokorelasi (ACF) dan fungsi autokorelasi parsial (PACF). Fungsi autokorelasi (ACF) mengukur seberapa kuat hubungan antara $X_{t}$ dan $X_{t+h}$. Fungsi autokorelasi untuk sampel $x_{1}, x_{2}, \cdots, x_{n}$, adalah [2]:

$$
\hat{\rho}_{h}=\frac{\sum_{t=1}^{n-h}\left(X_{t+h}-\bar{X}\right)\left(X_{t}-\bar{X}\right)}{\sum_{t=1}^{n}\left(X_{t}-\bar{X}\right)^{2}} .
$$

Adapun fungsi autokorelasi parsial (PACF) digunakan untuk menunjukkan besarnya hubungan antara $X_{t}$ dan $X_{t+h}$, dengan menganggap pengaruh nilai variabel dari lag yang lain adalah konstan. Fungsi autokorelasi parsial untuk sampel adalah $[4]$ :

$$
\hat{\Phi}_{h h}=\frac{\hat{\rho}_{h}-\sum_{j=1}^{h-1} \hat{\Phi}_{h-1, j} \hat{\rho}_{h-j}}{1-\sum_{j=1}^{h-1} \hat{\Phi}_{h-1, j} \hat{\rho}_{j}} .
$$

\subsection{Seasonal Autoregressive Integrated Moving Average(SARIMA)}

Model $S A R I M A$ merupakan model $A R I M A$ yang mengandung unsur musiman. Secara umum bentuk model $A R I M A$ pola seasonal atau $\operatorname{SARIMA}(p, d, q)(P, D, Q)^{S}$ adalah sebagai berikut [4]:

$$
\phi_{p}(B) \Phi_{P}\left(B^{s}\right)(1-B)^{d}\left(1-B^{s}\right)^{D} X_{t}=\theta_{q}(B) \Theta_{Q}\left(B^{s}\right) \varepsilon_{t}
$$

dimana:

$$
\begin{aligned}
\Phi_{P}\left(B^{s}\right) & :\left(1-\Phi_{1} B^{S}-\Phi_{2} B^{2 S}-\cdots-\Phi_{P} B^{P S}\right), \\
\Theta_{Q}\left(B^{S}\right) & :\left(1-\Theta_{1} B^{S}-\Theta_{2} B^{2 S}-\cdots-\Theta_{Q} B^{Q S}\right), \\
\phi_{p}(B) & :\left(1-\phi_{1} B-\phi_{2} B^{2}-\cdots-\phi_{p} B^{p}\right) \\
\theta_{q}(B) & :\left(1-\theta_{1} B-\theta_{2} B^{2}-\cdots-\theta_{q} B^{q}\right) .
\end{aligned}
$$


130 Prawati Ningsih dkk.

\subsection{Pemilihan Model Terbaik}

Pemilihan model terbaik pada model deret waktu adalah Akaike Information Criterion (AIC) dan Bayesian Interior Criterion (BIC). AIC dan BIC digunakan untuk melihat kececokan antara model dengan data. $A I C$ digunakan untuk menentukan model yang dapat menjelaskan data dengan jumlah parameter yang baik untuk menduga data. Sedangkan $B I C$ digunakan untuk memperbaiki sifat pendugaan yang terlalu tinggi dari $A I C$. Bentuk umum $A I C$ dan $B I C$ dapat ditulis seperti persamaan (2.6) dan (2.7) [3].

$$
\begin{aligned}
& A I C=n \ln \sum_{t=1}^{n} e_{t}^{2}+2 k \\
& B I C=n \ln \sum_{t=1}^{n} e_{t}^{2}+k \ln n,
\end{aligned}
$$

dimana $\sum_{t=1}^{n} e_{t}^{2}$ adalah jumlah kuadrat sisaan, $n$ adalah banyaknya dara dan $k$ adalah jumlah parameter yang diduga.

\section{Metode Penelitian}

Data jumlah kedatangan wisatawan mancanegara ke Sumatera Barat melalui Bandara Internasional Minangkabau berasal dari website resmi Badan Pusat Statistik Provinsi Sumatera Barat yang digunakan dari bulan Januari tahun 2012 sampai dengan bulan Desember 2018. Berikut merupakan tahap dalam menyelesaikan peramalan dengan menggunakan model SARIMA:

(1) Identifikasi Data.

Melakukan pemeriksaan dan mengidentifikasi plot data secara umum. Jika data belum stasioner, maka dilakukan proses untuk menstasionerkan data.

(2) Identifikasi Model.

Menganalisa grafik $A C F$ dan $P A C F$ untuk menduga kemungkinan dari orde $p$ dan $q$ untuk non musiman dan orde $P$ dan $Q$ untuk orde musiman.

(3) Pendugaan Parameter Model.

Pendugaan model dilakukan untuk mencari koefisien parameter model yang cocok. Selanjutnya model dugaan sementara yang signifikan akan dilakukan evaluasi model dengan melihat nilai $A I C$ dan $B I C$.

(4) Diagnostik Model.

Diagnostik merupakan pemeriksaan uji signifikan model dan uji asumsi pada residual diantaranya uji non-autokorelasi, uji normalitas, dan uji efek heterokedastisitas.

(5) Peramalan dengan menggunakan model terbaik.

\section{Pembahasan}

Tahap pertama adalah melakukan identifikasi data dengan melihat plot data. Pada Gambar 1 diberikan plot jumlah kedatangan wisatawan mancanegara ke Sumatera Barat melalui Bandara Internasional Minangkabau terhadap waktu. 


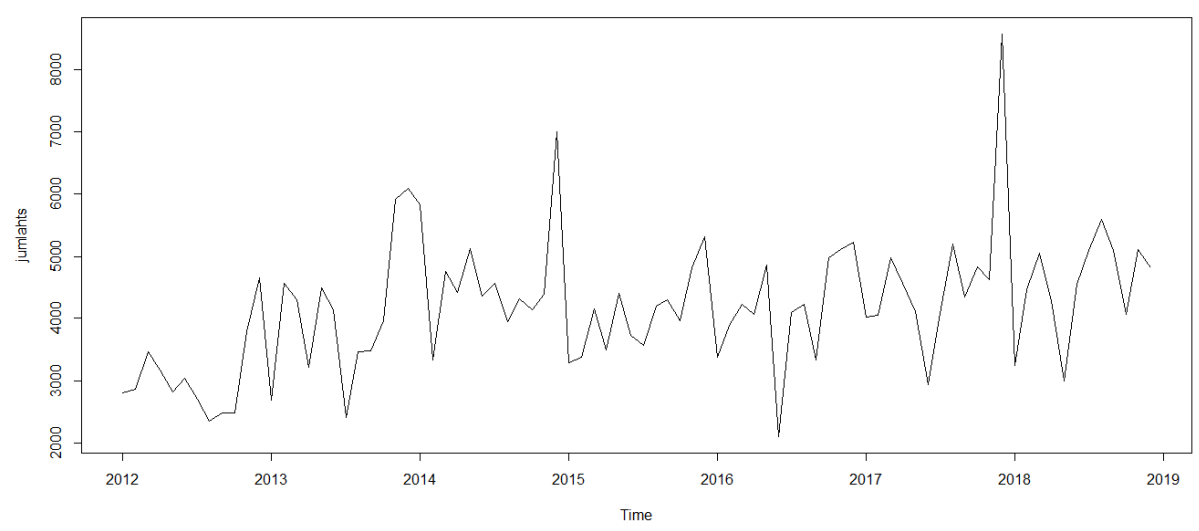

Gambar 1. Plot Data Jumlah Kedatangan Wisatawan Mancanegara ke Sumatera Barat Melalui Bandara Internasional Minangkabau Tahun 2012-2016

Gambar 1 menunjukkan bahwa data stasioner terhadap nilai tengah karena plot data menunjukkan tidak adanya tren, tetapi data diduga tidak stasioner terhadap ragam, karena plot data tersebut bervariasi terhadap waktu.

Kestasioneran data terhadap nilai tengah dapat dilihat dengan menggunakan uji Augmented Dickey-Fuller (ADF). Dari hasil pengujian ADF diperoleh nilai uji sebesar -3.6341 dan nilai kritis tabel dengan $\alpha=0.05$ sebesar 0.0354 , sehingga nilai uji lebih kecil dari nilai kritisnya. Hal ini menunjukkan bahwa data sudah stasioner terhadap nilai tengah. Selanjutnya untuk melihat kestasioneran terhadap ragam dapat dilihat dari transformasi Box-Cox. Hasil pengujian Box-Cox diperoleh nilai $\lambda=0.22$. Berdasarkan nilai yang diperoleh diketahui bahwa data belum stasioner terhadap ragam sehingga perlu dilakukan transformasi yaitu $X_{t}^{0.22}$, setelah itu dilakukan pengujian Box-Cox kembali dan diperoleh nilai $\lambda=1.0048 \approx 1$ artinya transformasi dihentikan dan ragam sudah konstan.

Tahap berikutnya adalah melakukan identifikasi orde $p, q, P, Q$. Orde $p, q, P, Q$ dapat diketahui dari plot $A C F$ dan $P A C F$. Pada Gambar 2 ditampilkan plot $A C F$ dan $P A C F$ dari data yang telah ditransformasi. Dari Gambar 2 terlihat bahwa pada plot $A C F$ data cut off setelah lag 3 sehingga diduga orde $q=3$, sedangkan pada plot $P A C F$ data cut off setelah lag 1 sehingga diduga orde $p=1$.

Pada Gambar 2 terlihat bahwa data masih mengandung musiman. Untuk itu perlu dilakukan proses differencing musiman untuk menghilangkan musiman dengan periode $S=12$. Pada Gambar 3 ditampilkan plot $A C F$ dan $P A C F$ data hasil differencing musiman. Dari Gambar 3 dapat dilihat bahwa plot $A C F$ signifikan pada lag 1 sehingga diduga orde $Q=1$, sedangkan pada plot $P A C F$ data signifikan setelah lag 2 sehingga diduga orde $P=2$.Setelah itu akan dilakukan pemodelan SARIMA, yaitu dengan cara mencoba-coba (trail and error) untuk mendapatkan hasil yang baik.

Berdasarkan hasil yang diperoleh, peramalan jumlah kedatangan wisatawan mancanegara ke Sumatera Barat melalui Bandara Internasional Minangkabau yang 
Series $x^{\wedge} 0.22$

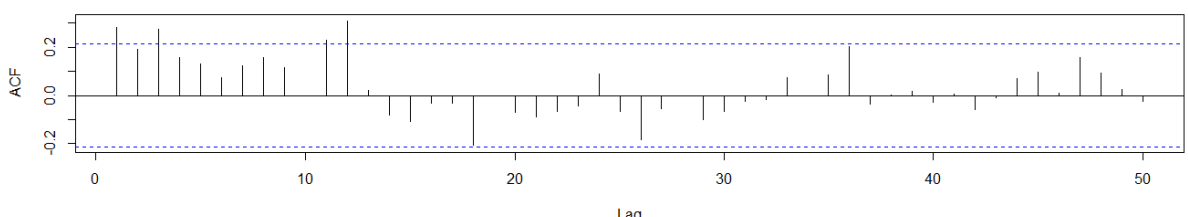

Series $x^{\wedge} 0.22$

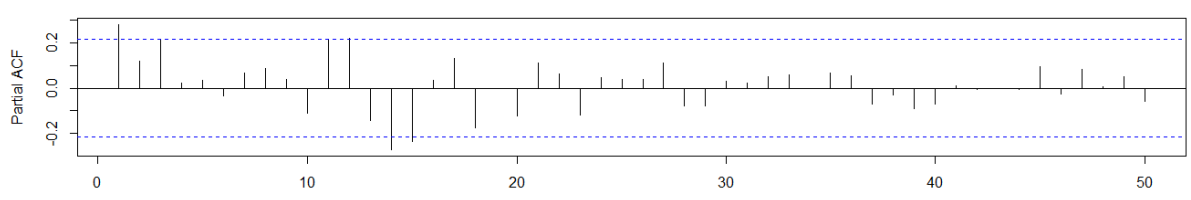

Lag

Gambar 2. Plot $A C F$ dan PACF Data Transformasi

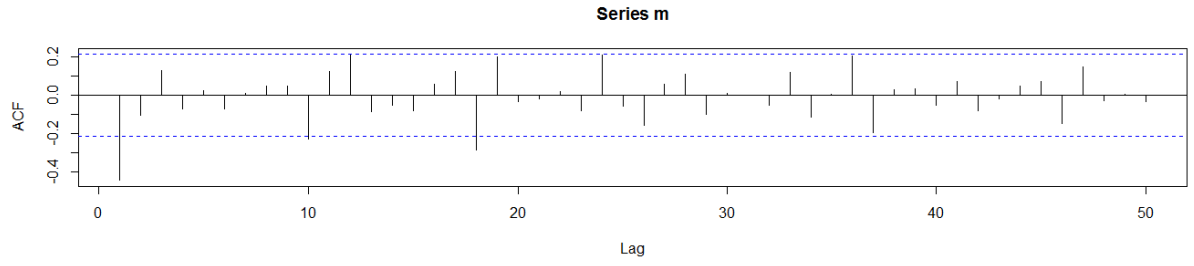

Series $\mathrm{m}$

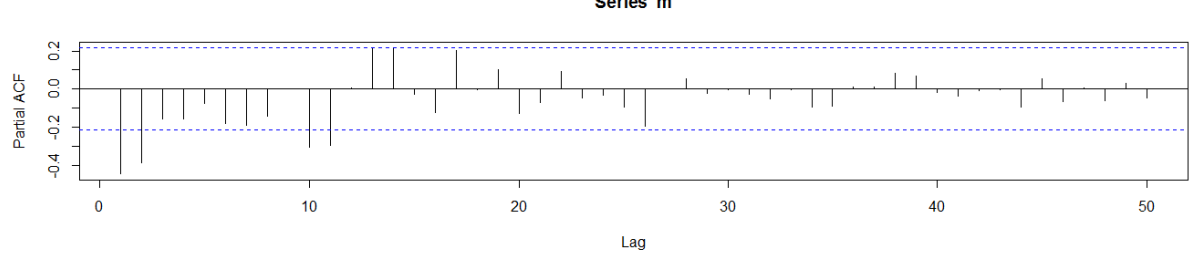

Gambar 3. Plot ACF dan PACF Data Differencing

paling tepat adalah pada model $\operatorname{SARIMA}(1,0,1)(2,1,0)^{12}$ karena nilai $A I C$ dan $B I C$ model tersebut merupakan nilai yang terkecil dari model-model SARIMA yang signifikan yaitu sebesar 1194.486 dan 1205.869 .

Berikut bentuk umum dari persamaan model $\operatorname{SARIMA}(1,0,1)(2,1,0)^{12}$ :

$$
\left(1-\phi_{1} B\right)\left(1-\Phi_{1} B^{12}-\Phi_{2} B^{24}\right)\left(1-B^{12}\right) X_{t}=\left(1-\theta_{1} B\right) \varepsilon_{t} .
$$

Bentuk persamaaan (4.1) dapat diuraikan menjadi:

$$
\begin{aligned}
X_{t} & =\phi_{1} X_{t-1}+\left(1+\phi_{1}\right) X_{t-12}-\left(\phi_{1}+\phi_{1} \Phi_{1}\right) X_{t-13}+\left(\Phi_{2}-\Phi_{1}\right) X_{t-24} \\
& -\left(\phi_{1} \Phi_{2}+\phi_{1}+\phi_{1} \Phi_{1}\right) X_{t-25}-\Phi_{2} X_{t-36}+\left(\phi_{1} \Phi_{2}\right) X_{t-37}-\theta_{1} \varepsilon_{t-1}+\varepsilon_{t} .
\end{aligned}
$$

Berdasarkan Persamaan (4.2) dapat dibangun model dengan menggunakan nilai 
taksiran parameter, yaitu:

$$
\begin{aligned}
X_{t} & =0.9437 X_{t-1}+0.2658 X_{t-12}-0.2508 X_{t-13}+0.1833 X_{t-24} \\
& +0.2691 X_{t-25}+0.5509 X_{t-36}-0.5199 X_{t-37}+0.7710 \varepsilon_{t-1}+\varepsilon_{t} .
\end{aligned}
$$

Model $\operatorname{SARIMA}(1,0,1)(2,1,0)^{12}$ juga memenuhi semua uji asumsi residual diantaranya uji non-autokorelasi, uji normalitas, dan uji heterekedastisitas. Hasil uji non-autokorelasi dengan uji L-jung Box menunjukkan bahwa residual dari model sudah memenuhi asumsi tidak terdapat autokorelasi pada residual yang dapat dilihat pada $p$-value untuk masing-masing lag $>0.05$. Pada uji Jarque-Berra, diperoleh nilai uji Jarque Berra sebesar 3.1555, karena nilai Jarque Berra $<\chi_{0.05(2)}^{2}=5.99$ artinya terima $H_{0}$ atau residual model berdistribusi Normal. Dan pada uji efek heteroskedastisitas dengan menggunakan uji white diperoleh $p$-value 0.7591 , karena $p$-value $>\alpha(0.05)$ artinya terima $H_{0}$ atau tidak terdapat efek heterokedastisitas.

Pada Tabel 1 diberikan hasil peramalan pada tahun 2019 dengan model $\operatorname{SARIMA}(1,0,1)(2,1,0)^{12}$.

\begin{tabular}{|c|c|}
\hline Bulan & Data Hasil Ramalan \\
\hline Januari & 3498 \\
\hline Februari & 4106 \\
\hline Maret & 4621 \\
\hline April & 4244 \\
\hline Mei & 4253 \\
\hline Juni & 2935 \\
\hline Juli & 4385 \\
\hline Agustus & 4796 \\
\hline September & 4008 \\
\hline Oktober & 4728 \\
\hline November & 5046 \\
\hline Desember & 5745 \\
\hline
\end{tabular}

Tabel 1. Hasil Peramalan Model $\operatorname{SARIMA}(1,0,1)(2,1,0)^{12}$

Pada Gambar 4 diberikan plot jumlah kedatangan wisatawan mancanegara ke Sematera Barat melalui Bandara Internasional Minangkabau untuk data aktual dan ramalan.

\section{Kesimpulan}

Berdasarkan pengolahan data jumlah kedatangan wisatawan mancanegara ke Sumatera Barat melalui bandara Internasional Minangkabau dengan metode $S A R I M A$, diperoleh model terbaik berdasarkan nilai $A I C$ dan $B I C$ yang terkecil yaitu model $S A R I M A(1,0,1)(2,1,0)^{12}$. Dari model terbaik yang diperoleh maka dilakukan peramalan jumlah kedatangan wisatawan mancanegara ke Sematera Barat melalui Bandara Internasional Minangkabau pada bulan Januari 2019 hingga Desember 2019. Diprediksi bahwa jumlah pengunjung wisatawan mancanegara tertinggi yaitu pada bulan Desember, dengan jumlah pengunjung 5745 . 


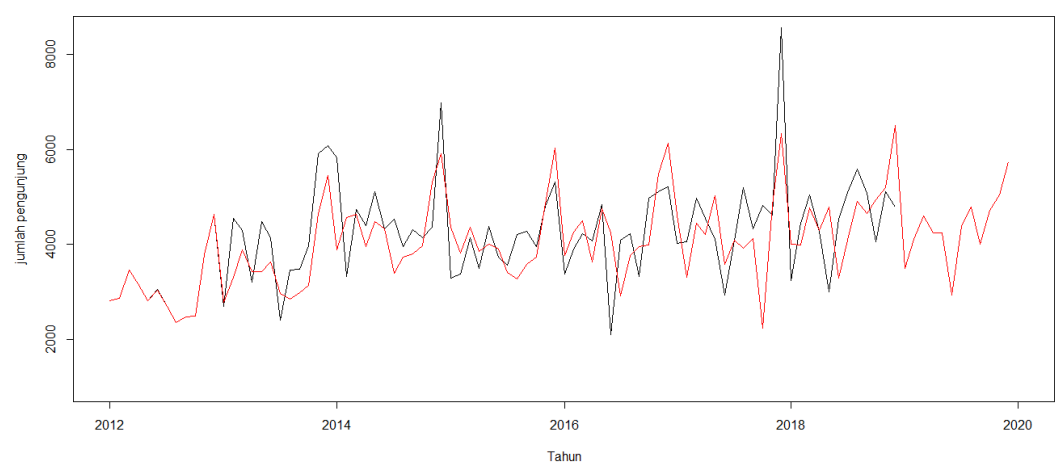

Gambar 4. Plot Data Aktual Dan Hasil Ramalan Jumlah Kedatangan Wisatawan Mancanegara ke Sumatera Barat Melalui Bandara Internasional Minangkabau

\section{Ucapan Terima kasih}

Penulis mengucapkan terima kasih kepada Bapak Dr. Dodi Devianto, Ibu Dr. Arrival Rince Putri dan Ibu Hazmira Yozza, M.Si yang telah memberikan kritikan dan saran untuk perbaikan dalam tulisan ini.

\section{Daftar Pustaka}

[1] Crier, J.D. and K.S. Chan. 2008. Time Series Analysis with Aplications in R. 2nd Edition. Springer, New York.

[2] Makridakis, S., S.C. Wheelwright., and V.E. McGee. 1992. Metode dan Aplikasi Peramalan. Erlangga, Jakarta.

[3] Montgomery, D.C., C.L. Jennings., And M. Kulahci. 2007. Introduction to Time Series Analysis and Forecasting. John Wiley And Son, New York.

[4] Wei,W.W.S. 2006. Time Series Analysis: Univariate and Multivariate Methods. Second Edition. Pearson Education, Amerika. 